\title{
Cortactin is a sensitive biomarker relative to the poor prognosis of human hepatocellular carcinoma
}

Gang Zhao ${ }^{1,2}$, Zi-ming Huang ${ }^{3}$, Ya-Lin Kong ${ }^{1}$, Dong-Qing Wen ${ }^{4}$, Yu Li, Li Ren ${ }^{5}$ and Hong-Yi Zhang ${ }^{\text {** }}$

\begin{abstract}
Background: Cortactin is an important regulator involved in invasion and migration of hepatocellular carcinoma (HCC). The aim of this study was to elucidate the forecasting role of cortactin in resectable HCCs.

Methods: We compared the invasiveness and motility among liver epithelial cell line and HCC cell lines by using Transwell assay and wound healing assay. We further investigated the CTTN mRNA expression by real-time PCR. Next, 91 HCC and 20 normal liver tissue samples were detected by IHC and real-time PCR. Finally, we analyzed the clinicopathologic features and survival time of the HCC cases.

Results: We identified that HepG2, LM3, and SK-Hep-1 had more invasiveness and motility $(P<0.05)$. Compared with liver epithelial cell line, CTTN expression was higher in LM3, HepG2, and MHCC97-L $(P<0.01)$ and lower in SK-Hep-1 ( $P<0.05)$. IHC examination showed cortactin expression was closely relative to TNM stage (AJCC/UICC), cancer embolus, and metastasis $(P<0.01)$. Cortactin overexpression indicated a longer survival time of $52 \pm 8.62$ months and low expression of a shorter survival time of $20 \pm 4.95$ months $(P<0.01)$. Cortactin examination has more predictive power in patients with Child-Pugh grade A and BCLC stage 0-B.

Conclusions: Overexpression of cortactin is closely associated with poor human HCCs prognosis that caused by cancer embolus and metastasis. Cortactin and CTTN should be used for differentiating varieties of survival for patients after HCC resection.
\end{abstract}

Keywords: Hepatocellular carcinoma, Cortactin, Neoplasm invasiveness, Prognosis

\section{Background}

Hepatocellular carcinoma (HCC) is one of the most common malignant tumors in the world [1]. In China, $\mathrm{HCC}$ has been one of the leading causes of cancer death despite remarkable improvement in diagnostic and therapeutic techniques [2]. Although the prognosis remains poor, there is no specific method to predict long-term survival time of HCC patients [3]. Thus, differentially subsequent treatment for HCC patients cannot be performed after initial operation. The point of view has been taken that poor prognosis of HCC is mainly because of the high incidence of hematogenous intrahepatic metastasis after initial treatment [4]. In

\footnotetext{
*Correspondence: kjzygdwk@163.com

${ }^{1}$ Department of Hepatobiliary Surgery, Chinese PLA Air Force General Hospital, No.30 Fucheng Road, Haidian District, Beijing 100142, China Full list of author information is available at the end of the article
}

essence, invasiveness of hepatocarcinoma cells play a crucial role in HCC metastasize and recurrence. Furthermore, cytoskeleton remodeling is required for tumor cell invasion and migration [5]. The molecular closely involved in cytoskeleton remodeling may be valid candidates which can predict prognosis of patients with cancer. Oligonucleotide array technology, a highthroughput method of monitoring gene expression, showed that the molecular signatures were apparently different between highly metastatic HCC cell lines and non-metastatic HCC cell lines. Among these candidates, CTTN, a gene related to tumor cell invasion and migration, for which the encoding protein is named cortactin, may be a potential molecular marker that can predict prognosis of cancer patients [6]. In addition, it has been well documented that CTTN is amplified in several other human cancers leading to cortactin overexpression

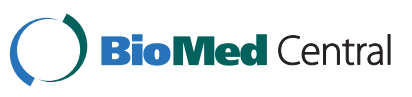


[7,8]. Although stable overexpression of cortactin does not cause morphological changes or affect proliferation, it makes cells more motile and invasive [9]. It has been proved that if cortactin can be overexpressed in a nonmetastatic HCC cell line it will increase cell motility and resulted in increased metastatic formation [6]. Conversely, cortactin knockdown can decrease tumor cell motility and invasion $[6,10]$. Forecasting role of cortactin has been investigated in head and neck squamous cell carcinomas and even in HCC [6,11]. As we know, however, no study has carried out follow-up on a series of cases with HCC. In this study, to investigate whether cortactin and CTTN could become a sensitive and specific biomarker to predicate HCC prognosis, we first selected five cell lines, including one liver epithelial cell line and four HCC cell lines, to detect their ability of invasion and migration. We then compared their expression level of CTTN mRNA. We also collected patients who were performed hepatectomy and examined their tissue samples. Cortactin and CTTN mRNA were examined respectively. To confirm whether cortactin and CTTN expression are related to the survival of HCC patients, we followed up this series of cases and compared the survival data of different expression levels.

\section{Methods}

\section{Cell culture and liver tissue}

The liver epithelial cell line, QSG-7701, and HCC cell lines, HepG2, MHCC97-L, and SK-Hep-1, were obtained from the Beijing Institute of Transfusion Medicine. Another HCC cell line, LM3, was obtained from the Chinese PLA General Hospital. All the cells were maintained in DMEM $(\mathrm{H})$ supplemented with $10 \%$ fetal bovine serum (FBS). Ninety-one random sampled HCC patients (22 women, 69 men; mean age, 54 years) were studied retrospectively. The patients had been recruited in the PLA Air Force General Hospital from 2002 to 2009. All the patients have been performed hepatectomy for resectable hepatocellular carcinoma. No radiotherapy and chemotherapy were undergone before the operation. The other 20 hepatic haemangioma cases were randomly sampled as the control group. The final pathological diagnoses of 111 cases were definite. Ninety-seven tissue blocks were acquired and refrigerated in liquid nitrogen right after removal out of the body, including 77 HCC tissues and 20 normal liver tissues adjacent to haemangioma. In 91 HCCs, 14 tissues were not acquired to be refrigerated for the reason of too small tumor size or inconvenient during operation. Patients and disease characteristics are shown in Table 1. Sections from 91 HCC histological paraffin-embedded specimens were used for cortactin immunohistochemistry. Seventy-seven HCC tissue blocks and 20 normal liver tissue blocks were analyzed by real-time PCR to investigate CTTN
Table 1 Cortactin immunohistochemical detection in 91 HCCs

\begin{tabular}{|c|c|c|c|}
\hline & \multicolumn{2}{|c|}{ Cortactin IHC score } & \multirow[t]{2}{*}{$P$} \\
\hline & $0-3$ & $4-6$ & \\
\hline Cases $(n)$ & 43 & 48 & \\
\hline \multicolumn{3}{|l|}{ Gender } & 0.846 \\
\hline Male & 33 & 36 & \\
\hline Female & 10 & 12 & \\
\hline Mean age $(\text { years })^{a}$ & $52.81 \pm 1.74$ & $54.46 \pm 1.68$ & 0.667 \\
\hline \multicolumn{3}{|l|}{$\mathrm{HBsAg}$} & 0.265 \\
\hline$(-)$ & 9 & 15 & \\
\hline$(+)$ & 34 & 33 & \\
\hline $\operatorname{AFP}(\mu \mathrm{g} / \mathrm{L})^{\mathrm{a}}$ & $276.79 \pm 57.33$ & $319.6 \pm 61.57$ & 0.614 \\
\hline \multicolumn{3}{|l|}{ Liver cirrhosis } & 0.523 \\
\hline No & 10 & 14 & \\
\hline Yes & 33 & 34 & \\
\hline Maximal size $(\mathrm{mm})^{\mathrm{a}}$ & $6.64 \pm 0.84$ & $7.76 \pm 0.66$ & 0.531 \\
\hline \multicolumn{3}{|l|}{ Liver capsule integrity } & 0.054 \\
\hline Complete & 34 & 29 & \\
\hline Incomplete & 9 & 19 & \\
\hline \multicolumn{3}{|l|}{ Tumor nodules $(n)$} & 0.084 \\
\hline Single & 34 & 30 & \\
\hline Multiple & 9 & 18 & \\
\hline \multicolumn{3}{|c|}{ Cancer embolus or metastasis } & $0.000^{k}$ \\
\hline No & 40 & 21 & \\
\hline Yes & 3 & 27 & \\
\hline \multicolumn{3}{|c|}{ Edmondson classification } & 0.375 \\
\hline$|-| \mid$ & 21 & 19 & \\
\hline||$|-| \mathrm{IV}$ & 22 & 29 & \\
\hline \multicolumn{3}{|c|}{ TNM stage (AJCC/UICC) } & $0.000^{b}$ \\
\hline$|-| \mid$ & 32 & 15 & \\
\hline III-IV & 11 & 33 & \\
\hline
\end{tabular}

${ }^{a}$ Mean \pm SE.

${ }^{\mathrm{b}} \mathrm{P}<0.01$.

mRNA expression level. Written informed consent was obtained from all patients, and this study was approved by the Ethics Committee of Chinese PLA Air Force General Hospital.

\section{The determination of clinical stage}

Tumor size and number, liver function test, prothrombin time, performance status, and cancer-related symptoms were investigated. If esophagogastric varices, ascites, splenomegaly and a platelet count $<100,000 / \mathrm{mm}^{3}$, the portal hypertension was defined. All patients underwent serum $\alpha$-fetoprotein (AFP), abdominal ultrasound, and four-phase dynamic computed tomography (CT) examination. In cases with another intrahepatic nodule not 
typical of HCC by dynamic CT and AFP, evaluations were made by dynamic magnetic resonance imaging (MRI) or positron emission tomography (PET)-CT. The biopsy was applied when imageology examination could not make a final diagnosis. The chest CT was carried out when the patient had positive present of diagnostic chest $\mathrm{X}$-ray radiology which is as a routine examination for all patients. A bone scan was necessary when the patient have chief complaint of osteodynia. The hepatic functional reserve was evaluated by ChildPugh grade system which was classified as A, B, and C. BCLC stage system was applied to determine the clinical stages. HCC patients were classified into five stages including: 0 , very early; A, early; B, intermediate; $\mathrm{C}$, advanced; or D, terminal. Final HCC stages were determined after operation, histopathology, and a follow-up examination [12].

\section{Transwell invasion assay}

To hydrate the matrigel layer, the upper chamber of a transwell cell culture insert (Corning 3422) was filled with $100 \mu \mathrm{L} \operatorname{DMEM}(\mathrm{H})$ medium without FBS and incubated at $37^{\circ} \mathrm{C}$ for $1 \mathrm{~h}$. Cells were suspended with serumfree $\operatorname{DMEM}(\mathrm{H})$ medium to the concentration of $5 \times 10^{5}$ cells $/ \mathrm{mL}$. Filled $200 \mu \mathrm{L}$ cell suspension to upper chamber and $600 \mu \mathrm{L} \operatorname{DMEM}(\mathrm{H})$ medium with $10 \% \mathrm{FBS}$ to the bottom chamber. The inserts were placed in the cell culture incubator at $37^{\circ} \mathrm{C}$ for $24 \mathrm{~h}$. The cell was fixed by placing each insert into $90 \%$ ethanol and the cell was stained with $1 \%$ crystal violet for $30 \mathrm{~min}$. Five high power fields $(\times 100)$ were randomly selected in each chamber to observe the cells and Cell Counter software was used to count the stained invaded cells. Each experimental group was repeated three times.

\section{Wound healing assay}

Cells were seeded into 24-well tissue culture plate in a density that reached $70 \%$ to $80 \%$ confluence as a monolayer after $24 \mathrm{~h}$ of growth. The monolayer was scratched with a pipette tip across the center to create a cross in each well. The well was washed twice with medium to remove the detached cells. The cells were grown for additional $96 \mathrm{~h}$ in fresh medium. Four views of each well were documented and the gap distance was quantitatively evaluated using WCIF Image software. Each experimental group was repeated three times.

\section{Immunohistochemical staining}

Labeled streptavidin-biotin peroxidase complex method was used [13]. Immunohistochemistry with cortactin (Cortactin Ab, 1:50; Cell Signaling) was performed on sections of formalin-fixed (7.5\% buffered formalin) and paraffin-embedded representative tumor tissues from all 91 carcinomas. Tissue blocks were cut to $4 \mu \mathrm{m}$, then mounted on silicone-coated slides, deparaffinized with xylene, $100 \%$ ethanol and $95 \%$ ethanol by turns, and heated in $10 \mathrm{mM}$ sodium citrate buffer ( $\mathrm{pH}$ 6.0) using a microwave oven for $10 \mathrm{~min}$ at $95^{\circ} \mathrm{C}$. Before primary antibody incubation, incubated sections in 3\% hydrogen peroxide and blocked sections with 5\% goat serum. Primary antibodies were incubated overnight at $4^{\circ} \mathrm{C}$. Biotinylated secondary antibody and $\mathrm{ABC}$ avidin/biotin method was used for visualizing positive reactions. After $A B C$ reagent was incubated, the sections were developed with 3 , 3'-diaminobenzidine and counterstained with hematoxylin. The sections were washed, dehydrated, and mounted as routine.

\section{Immunohistochemical scoring}

For each stained section, the fraction of the immunostained cells was recorded, and the staining intensity was then initially categorized according to arbitrarily predefined criteria into three ranks, including: 0 , very weakly or weakly positive; 1 , moderately positive; and 2 , strongly positive. Five high power fields $(\times 400)$ were randomly selected in each section, and no fewer than 1,000 tumor cells were observed. The percentage of positivity was calculated. The percentage was scored from 0 to 4 according to the percentage of positive cells $(0,0-5 \% ; 1$, $6-25 \%$; 2, 26-50\%; 3, 51-75\%; 4, 76-100\%). Positive percentage score plus stain intensity score were the final score of each section $[14,15]$. The examiners were blinded to patients' clinical and histological (HE staining) profile. Two investigators evaluated the staining levels independently, after which any discordant evaluations were adjusted by connected microscopes and scored jointly.

\section{Single strand CDNA synthesis}

Trizol (Invitrogen) was used to isolate total RNA from cultured cells and tissue blocks following the manufacturer's instruction. RNA integrity was confirmed spectrophotometrically and by electrophoresis on $1 \%$ agarose gels [16]. For cDNA synthesis, $2 \mu \mathrm{g}$ total RNA of a sample were reverse-transcribed in a final reaction volume of $25 \mu \mathrm{L}$ containing M-MLV (Promega), random hexamers, dNTP, RNase inhibitor (TaKaRa). The reverse transcription reaction was performed under the following conditions: $70^{\circ} \mathrm{C}$ for $5 \mathrm{~min}$ followed cooling the tube immediately on ice; then at $25^{\circ} \mathrm{C}$ for $10 \mathrm{~min}, 37^{\circ} \mathrm{C}$ for $1 \mathrm{~h}$, and $85^{\circ} \mathrm{C}$ for $15 \mathrm{~min}$.

\section{Real-time PCR}

CTTN and GAPDH (glyceraldehyde phosphate dehydrogenase) gene were amplified by RT-PCR (reverse transcription-polymerase chain reaction) from one HCC samples. The products of each gene were respectively inserted into pMD18-T vector to build standard curves. 
The amount of standard substance copies was confirmed spectrophotometrically. The primer set 5'-TGAGTGTG TGTTCTTCCCCAAG-3' (forward) and 5'-CACGTG ACCTTCTGGAAAGACA-3' (reverse) [6] was used for CTTN. For standardization among the samples, GAPDH was used as internal reference gene and the expression of GAPDH in each sample was quantified by primer set 5'-AGAAGGCTGGGGCTCATTTG-3' (forward) and 5'AGGGGCCATCCACAGTCTTC-3' (reverse). $2 \times$ SYBR Premix Ex Taq (TaKaRa DRR041) was used and the reaction was performed at least three times for each sample. For the signal detection, Eppendorf Mastercycler ep realplex was programmed to an initial step of $10 \mathrm{~s}$ at $95^{\circ} \mathrm{C}$ and 40 thermal cycles of $5 \mathrm{~s}$ at $95^{\circ} \mathrm{C}, 25 \mathrm{~s}$ at $58^{\circ} \mathrm{C}$, and $15 \mathrm{~s}$ at $72^{\circ} \mathrm{C}$. After PCR reaction, melting curve reaction was performed. For analyzing the correlation between CTTN mRNA expression level and HCC invasiveness, the CTTN relative value to housekeeping gene GAPDH was calculated. One hemangioma-neighboring liver tissue sample became the $1 \times$ sample, and all the other quantities were expressed as an $n$-fold difference relative to this tissue.

\section{Statistical methods}

Data are expressed as means \pm SE. The level of cortactin mRNA in HCC cell lines and liver epithelial cell line was compared using unpaired $t$-test. The correlations between cortactin expression and clinicopathological features were analyzed by Pearson $x^{2}$ test and unpaired $t$-test. To compare the difference of CTTN mRNA relative magnitude, the variance analysis and KruskalWallis rank sum test was used. Cancer-specific survival time was calculated according to the Kaplan-Meier method. The log-rank test was used to compare the groups. $P<0.05$ was considered significant. All these analyses were performed using SPSS 17.0.

\section{Results}

\section{Invasiveness and motility}

Compared with QSG-7701, a non-cancerous liver epithelial cell line, the HCC cell lines HepG2, LM3, and SK-Hep-1 had more invasiveness $(P<0.01)$. But not all HCC cell lines had significant invasiveness such as MHCC97-L $(P>0.05)$. (Figures 1 and 2$)$ The metastasis ability of HepG2, LM3, and SK-Hep-1 were also significantly superior to QSG-7701 $(P<0.01, P<0.01$, $P<0.05)$. MHCC97-L had poor metastasis ability $(P>0.05)$ (Figures 3 and 4).

\section{CTTN quantity method}

The CTTN quantitative standard curve had finer linear relation when copy number of standard products was $1.6 \times 10^{3}-1.6 \times 10^{7}$, as well as GAPDH of $1.6 \times 10^{4}$ $1.6 \times 10^{7} \cdot R^{2}$ of both curves were $>0.99$. Single peak in the melt curve identified specific PCR amplification. CTTN specific peak localized at $88.0^{\circ} \mathrm{C}$ and GAPDH at $87.2^{\circ} \mathrm{C}$. Preliminary test was performed to evaluate the repeatability of CTTN quantity method before the final detection. Five specimens of HCC were detected at 4 different days with three repetitions each run. Threshold cycle values $(\mathrm{Ct})$ were collected to statistics the data. The outcome showed that the repeatability of each specimen had no significant difference within run and between days (data not shown).

\section{CTTN expression in HCC cell lines}

The amplification products of each cell lines were electrophoresed in $1.5 \%$ agarose gel to indicate correct amplification (Figure 5). ALL HCC cell lines have different expression levels of CTTN mRNA. Compared with QSG-7701, the CTTN mRNA of HepG2, LM3, and MHCC97-L overexpressed to 4.86-517.75 times $(P<0.01)$. SK-Hep-1 had low expression of 0.63 times $(P<0.05)$ (Figure 6).

\section{Cortactin expression in HCC tissues}

Among the 91 HCC tissues, cortacin positivity was observed in most sections. Only two cases were completely negative. Forty-three cases scored 0 to 3 and 48 cases scored 4 to 6 . In positive sections, cortactin immunoreactivity was detected on cytoplasm and showed diffuse staining. On positive cells, the cell membrane also showed positive staining with similar intensity of cytoplasm (Figure 7). Non-tumorous hepatocyte was almost negative regardless of chronic hepatitis or cirrhosis. However, bile duct epithelial cells and vascular endothelial cells always stained strongly. This could ensure the correct staining and the following scoring.

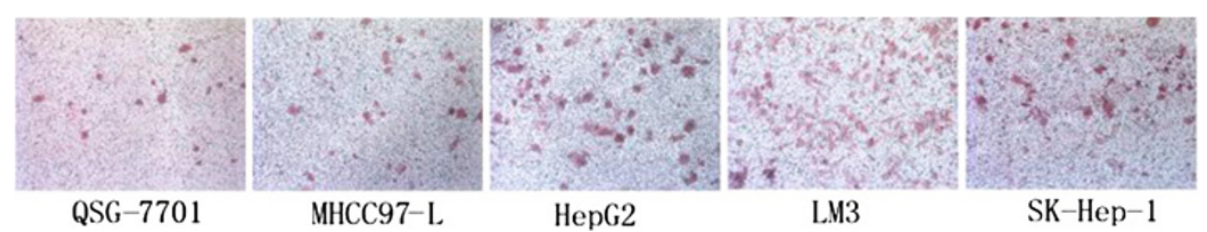

Figure 1 Decoration of puncture cells by five cell lines (100 × magnifications). 


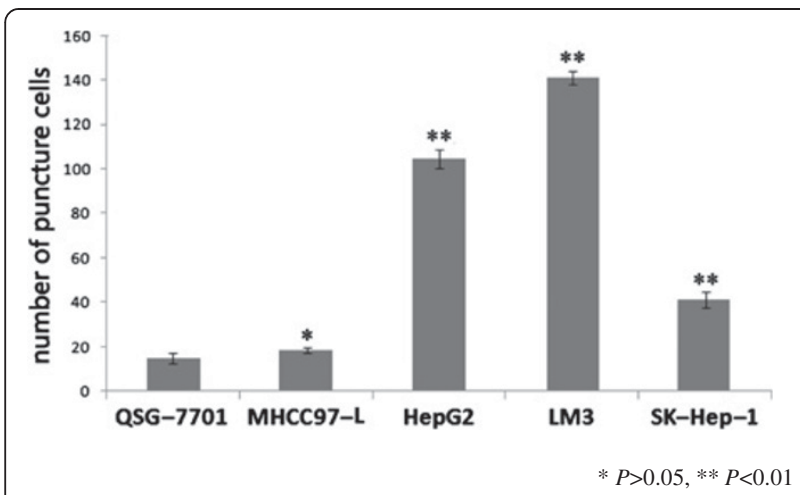

Figure $\mathbf{2}$ Counted number of puncture cells with five cell lines. QSG-7701 was the control cell lines, ${ }^{*} P>0.05,{ }^{* *} P<0.01$.

\section{Cortactin and clinicopathological features}

No significant difference was detected in gender, age, HBsAg, AFP, liver cirrhosis, tumor size, Edmondson classification, number of tumor nodules, and liver capsule integrity $(P>0.05)$. On the contrary, statistical difference was detected in the cases with cancer embolus in portal vein or distant neoplasm metastasis $(P<0.001)$ (Table 1).

\section{CTTN expression in HCC tissues}

According to IHC analysis, we grouped the $91 \mathrm{HCC}$ cases by whether cancer embolus and metastasis could be observed. Statistical results showed, although the CTTN relative values of no cancer embolus and metastasis group $(\mathrm{N})$, cancer embolus or metastasis group $(\mathrm{Y})$, and control group $(\mathrm{C})$ were tested normally distributed, the heterogeneity of variance existed between groups $(P<0.001)$. Kruskal-Wallis $\mathrm{H}$ test showed that the relative magnitude was significantly different between three groups. Paired comparison indicated the relative magnitude of Y group was much higher than that of the other two groups $(P<0.001)$. There was no statistical significance between the $\mathrm{N}$ and $\mathrm{C}$ groups $(P>0.05)$ (Table 2, Figure 8).

\section{Survival analysis}

The general median survival time of this group of 91 HCC patients was $37 \pm 6.62$ months. The authors carried out survival analysis by the classification of Child-Pugh grade. The result showed that grade $\mathrm{A}$ and $\mathrm{B}$ have a different median survival time of $43 \pm 2.89$ and $16 \pm 5.28$ months $(P<0.001)$. In this group of data, only one patient was identified with grade $C$ and survived 7 months after the initial diagnosis and operation (Figure 9A). According to BCLC stage system, three (3.3\%) patients were identified into group 0, 10 (11.0\%) into group A, 22 (24.2\%) into group B, 45 (49.5\%) into group C, and 11 (12.1\%) into group D. No patients died of HCC in group 0 . The median survival times of groups $A, B, C$, and D were $64,44 \pm 4.69,25 \pm 4.70$, and $9 \pm 2.75$ months, respectively. The significant deviation was found between the four groups $(P<0.001)$. The median survival time of group 0 and the standard error of group A could not be calculated for the censored data (Figure 9B).

Survival analysis was performed by two grouping methods, including by according to the CTTN relative magnitude and cortactin IHC score. For the convenience of statistical analysis, the natural logarithm of relative magnitude (RMLN) of each HCC specimen was calculated. The critical value was set at 2 . The difference between these two groups was detected $(P<0.001)$ with median survival time of $52 \pm 8.17$ months $($ RMLN $<2$ ) and $20 \pm 4.24$ months (RMLN $>2$ ) (Figure 10A). With IHC score grouping, it had also shown difference between the $0-3$ and $4-6$ groups $(P<0.001)$. The median survival time was $52 \pm 8.62$ months and $20 \pm 4.95$ months, respectively (Figure 10B).

\section{Discussion}

Recent research has shown that several tumor markers in serum are applied for the detection and forecasting on HCCs. The recommended screening strategy for patients with cirrhosis includes the determination of serum $\alpha$-fetoprotein (AFP) levels to detect HCC at an earlier stage. However, AFP is not satisfactory for the poor sensitivity and specificity. In addition to AFP, Lens culinaris
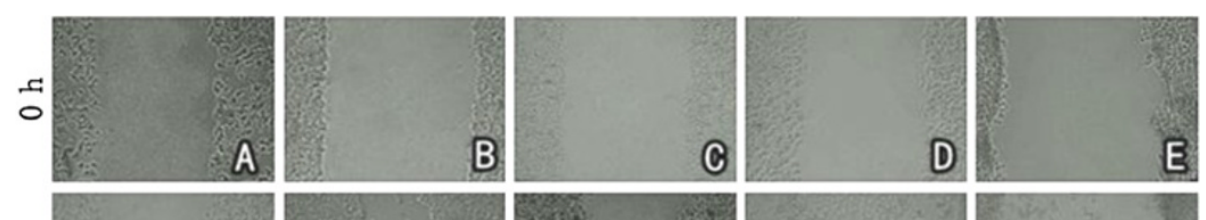

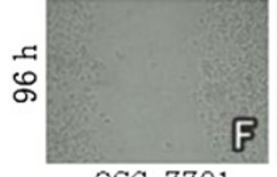

QSG-7701

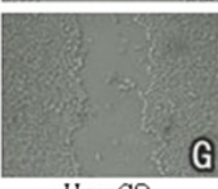

HepG2

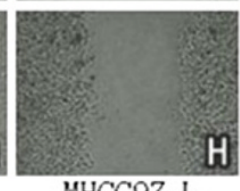

MHCC97-L

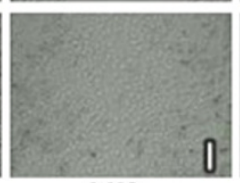

LM3

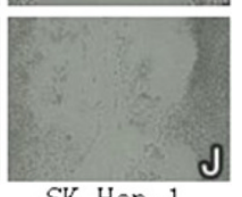

SK-Hep-1

Figure 3 Gap distance of scratch wound healing assay with five cell lines (50x magnification). 


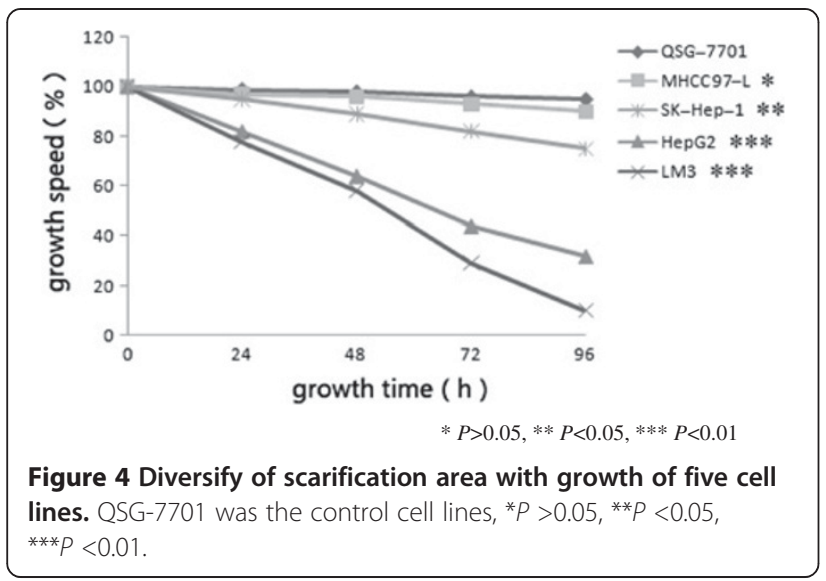

agglutinin-reactive AFP (AFP-L3), des- $\gamma$-carboxy prothrombin (DCP), glypican-3 (GPC-3), osteopontin (OPN), and several other biomarkers (such as squamous cell carcinoma antigen-immunoglobulin $\mathrm{M}$ complexes [SCCAIgM], alpha-1-fucosidase [AFU], chromogranin A [CgA], human hepatocyte growth factor, insulin-like growth factor) have been proposed as markers for the detection of HCC. Although these markers have their diagnostic and prognosis roles, none of them is optimal [17]. When used together, the DCP and AFP assays increase the sensitivity of detecting $\mathrm{HCC}$ in $>85 \%$ of patients. The specificity of the DCP assay appears to be superior to that of AFP [18]. Recently, there has been attention given to DCP because of its role in detecting HCC metastases and recurrence. The serum DCP level correlates with the presence of vascular invasion or intrahepatic metastases. Furthermore, DCP has been reported to be an independent prognostic factor for recurrence and survival after hepatic resection and other treatment. High DCP levels reflect the biologic aggressiveness and progression of HCC [18].

In addition to serum markers, the tremendous advances in the research on HCC tissues have shown expression difference in several genes. The most relevant result is the identification of an HCC-related index consisting of 13 genes (TERT, IGF2, GJB2, TEF, TIAM1, CXCL12, TOP2A, A2M, PLG, ARF, PDGFRA, MKI67, and THBS1), which allowed the diagnosis of HCC with a

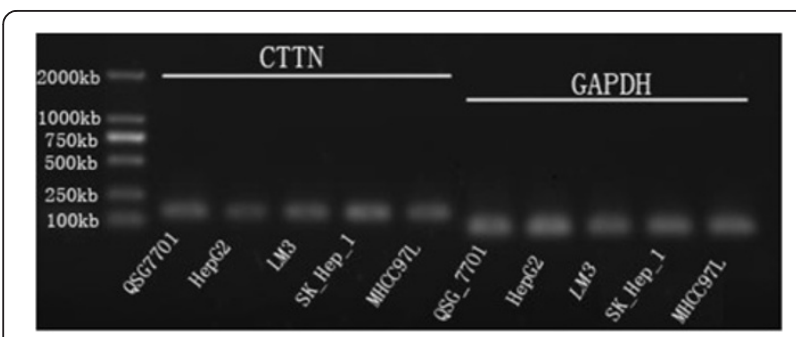

Figure 5 Electrophoresis of CTTN and GAPDH amplified products with five cell lines.

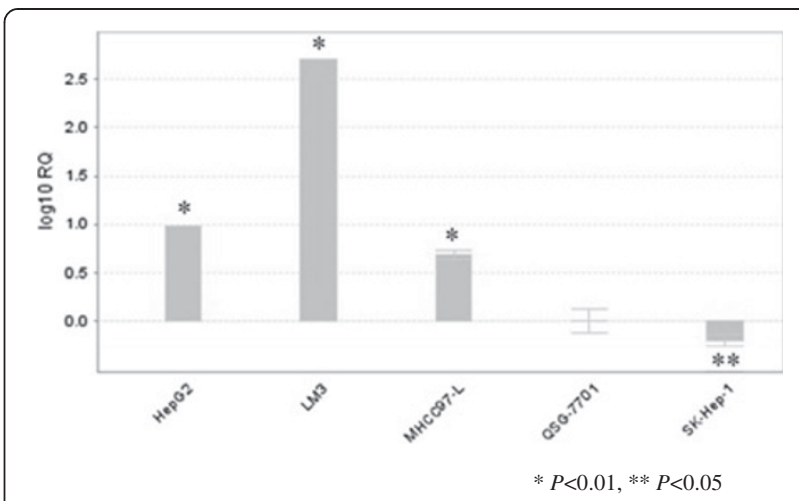

Figure 6 CTTN relative expression with five cell lines (logarithm). QSG-7701 was the control cell lines, ${ }^{*} P<0.01$, ${ }^{*} P<0.05$.

high sensitivity and a specificity of $100 \%$. Therefore, molecular analysis was shown to be a valuable tool for diagnosing HCC [16]. Another research has reported that 12 genes were expressed differently in initial HCC versus dysplastic nodules: five were overexpressed (TERT, glypican-3, gankyrin, survivin, TOP2A) and seven were subexpressed (LYVE1, E-cadherin, IGFBP3, PDGFRA, TGFA, cyclin D1, HGF) [19]. The same applies for biomarkers such as VEGF, angiopoietin 2, or the protooncogene c-Kit. They can refine prognostic prediction within statistical modeling but cannot yet be incorporated into assessment of an individual patient [12].

Cortactin was originally identified as one of the major substrates for the protein kinase Src [20]. Cortactin gene, CTTN (formerly designated EMS1), was identified to be amplified in several human cancers leading to cortactin overexpression [21]. It localizes in the 11q13 that is frequently overexpressed in breast and head and neck cancers and is tied to poor prognosis [22]. The amplification of 11q13 includes several molecular markers frequently associated with higher pathological stage, lymph node and distant metastasis, and decreased survival [23-25]. Due to the ubiquitous presence in cell motility structures, such as lamellipodia and invadopodia $[21,26]$, cortactin generates a great deal of interest in the role in tumor invasion. Cortactin contains a proline-rich region with c-Src tyrosine phosphorylation sites and a $\mathrm{SH} 3$ domain at the $\mathrm{COOH}$ terminus [27]. It also contains an $\mathrm{N}$-terminal acidic region that binds to the Arp2/3 complex [28]. Phosphorylation binding sites and SH3 domain are necessary for both activation and regulation of Arp2/3-complex-mediated branched actin assembly [29]. In addition to directly regulating actin assembly, cortactin also activates the neural WiskottAldrich syndrome protein (N-WASP), one of the strongest activators of the Arp2/3 complex [30,31]. By using transwell migration [9], wound closure [32], and single cell motility, it has been demonstrated that cortactin can enhance cell motility. On the other hand, siRNA against 


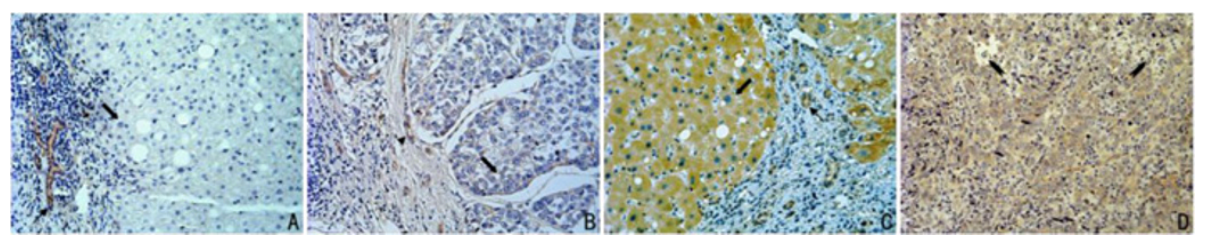

Figure 7 Cortactin expression in HCCs (400x magnification). (A) Bile duct epithelial cells (thin arrow) were strong positive, whereas HCC tissue (thick arrow) was negative. (B) Vascular endothelial cells (arrowhead) were positive with HCC tissue of weak positive expression. (C) HCC tissue showed strong positivity with diffuse staining of cytoplasm. (D) HCC tissue showed strong positive. Cancer cells were in a state of chaos with severe morphosis. Cancer embolus (double tail arrow) in portal vein can be seen.

cortactin inhibits cell motility [33,34]. Resent research suggest that cortactin may regulate endocytosis of integrins and growth factor receptors [35] or secretion of proteases [36] and extracellular matrix (ECM). These regulations have effects on cell motility, which dependent cell context.

Evidence shows that invasion is the most important factor which can raise recurrence rate of HCC [37]. Diffusion within or outside liver though portal vein, which originated from invasion of malignant cells, indicates poor prognosis of HCC [38]. Current studies demonstrate that overexpression of cortactin was closely associated with intrahepatic metastasis in human $\mathrm{HCC}$ and was a sensitive marker for HCC with intrahepatic metastasis [6]. But now it is lack of clinical research concerning the relation between CTTN expression level and HCC survival. Furthermore, to the best of our knowledge, no molecule markers can predict HCC prognosis independently and precisely. For this reason, we applied IHC and real-time PCR to detect cortactin expression in both protein and mRNA level with the intention of developing an efficacious approach to predict prognosis of HCC patients.

First, we compared five cell lines upon invasiveness and motility. The results showed that the invasion ability of three HCC cell lines were superior to the liver epithelial cell line. The motility of LM3, HepG2, and SK-Hep -1 were superior to QSG-7701, whereas MHCC97-L was not higher than that of QSG-7701. Interestingly, compared with liver epithelial cells, the CTTN expression of HCC cells may be overexpression, such as LM3, HepG2, and MHCC97-L, or low expression, such as SK-Hep-1. These results indicate that although CTTN overexpression may signify the higher invasiveness and motility, low expression may not be the sign of lower invasiveness and motility. The phenomenon was also observed in the examination of human tissue samples.

Subsequently, we detected cortactin IHC reactivity of HCCs. As our data showed, cortactin immunohistochemistry score was significantly associated with cancer embolus in portal vein and distant neoplasm metastasis, by both separately analysis and jointly analysis. This result is accordant with that of the other authors [6,38,39]. Apart from cancer embolus and distant metastasis, it is worth noting that liver capsule integrity may be the latent correlation factor to cortactin expression, though the $P$ values were 0.054 . A recent report has shown that extracapsular penetration is an important prognostic factor in human hepatocellular carcinoma [40]. In fact, if hemorrhage occurs because of spontaneous rupture in HCC or tumor cells break through pseudocapsule and form satellite lesion, the capsule integrity would definitely be destructed. The AJCC/UICC TNM stage system emphasize the role of neoplasm invasion and metastasis. We suppose that is the reason of correlativity between TNM stage and cortactin immunohistochemical reaction. Thus higher cortactin immunohistochemical score may imply higher TNM stage of HCC, which is significant to the clinical decision-making for the treatment to HCC.

This series of data also showed that CTTN mRNA expression level of cancer embolus or metastasis group (Y) was higher than no cancer embolus and metastasis group $(\mathrm{N})$ and control group $(\mathrm{C})$. But we found no difference between the $\mathrm{N}$ and $\mathrm{C}$ groups. This finding may indicated that CTTN mRNA expression level is not

Table 2 CTTN relative magnitude of the three groups

\begin{tabular}{llcccc}
\hline Group & $\boldsymbol{n}$ & $\overline{\mathbf{x}} \pm \mathbf{S E}$ & Minimal value & Maximal value & $\mathbf{9 5 \% C l}$ \\
\hline Control & 20 & $6.54 \pm 0.96$ & 1.00 & 15.72 & $4.53-8.56$ \\
No cancer embolus and metastasis & 52 & $7.75 \pm 0.70$ & 1.15 & 20.35 & $6.34-9.16$ \\
Cancer embolus or metastasis & 25 & $19.73 \pm 2.02$ & 2.99 & 42.47 & $15.56-23.90$ \\
\hline
\end{tabular}

Levene test of homogeneity of variance: $\mathrm{F}=10.57, P<0.001$; Kruskal-Wallis $\mathrm{H}$ test: $\mathrm{H}=31.13, P<0.001$. 


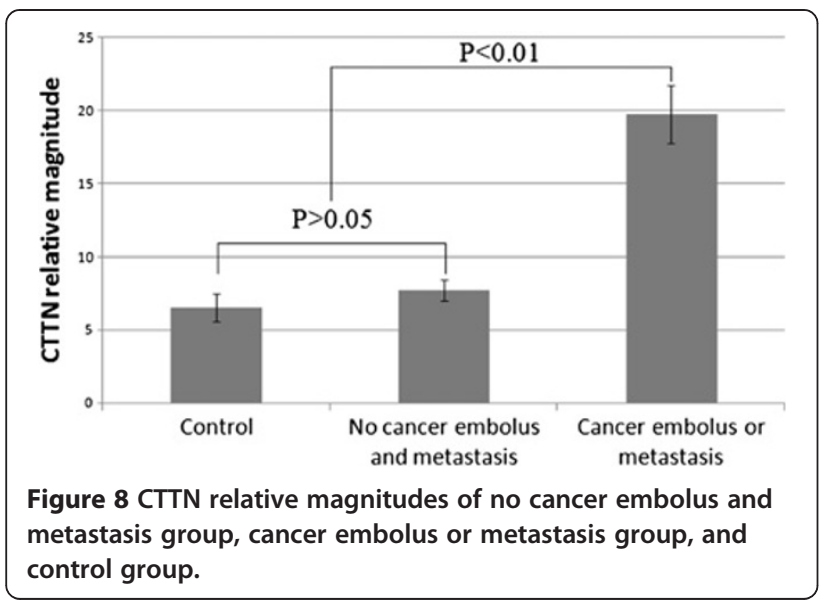

upregulated in non-metastatic HCCs. Just as the detected results from HCC cell lines, CTTN expression in MHCC97-L, a low invasiveness cell line, had the mildest upregulation. SK-Hep-1 is a special cell line that cannot form solid tumor. Its CTTN mRNA expression was not upregulation. We supposed that it is because cortactin have the role in regulation of the adhesion between cells. It has been reported that the adhesion regulated by cortactin may be relative to CD44, an important molecule to signal other cell surface receptors involved in regulating cell motility and invasion [33]. Thus, low expression of cortactin cannot promote the efficient adhesion which cannot lead HCC cells to format solid tumor, just as the biological behavior that SK-Hep-1 has.

In clinical practice, accurately predicting prognosis as far as possible is very important to the therapeutic decision-making for HCC patients. To investigate the prediction power by cortactin and CTTN, we bring into cortactin immunohistochemical score and natural logarithm of CTTN mRNA relative magnitude (RMLN). The survival analysis showed that both methods could distinguish the variance between high and low cortactin expression. Moreover, the median survival time was similar to each other. This congruous result further demonstrated the forecasting role of cortactin in both mRNA and protein level.

To preclude the confounding factor that hepatic functional reserve contributing to the survivals, we performed a survival analysis stratified by Child-Pugh grade. The results showed that in the stratum with Child-Pugh grade A, the median survival time was $55 \pm 7.38$ months in the patients whose cortactin IHC score was $0-3$; but it was only $30 \pm 7.18$ months in the patients whose cortactin IHC score was 4-6. The difference between the two cortactin expression levels was significant $(P<0.01)$ (Figure 11A). In stratum with Child-Pugh grade $B$, the median survival time was $28 \pm 3.54$ months and $12 \pm 3.74$ months in levels with cortactin scores of $0-3$ and 4-6, respectively. However, the difference between these two cortactin expression levels was not significant $(P=0.071)$ (Figure 11B). Hence the authors supposed that the decrease of hepatic functional reserve may reduce the survival time of HCC patients with cirrhosis and it is a confounding factor when cortactin was applied to predict survival time of patients.

Assessment of prognosis is a crucial step in management of patients with HCC. The BCLC strategy has been validated externally in prospective studies [41] and has been endorsed by several scientific associations [12]. Here the authors also analyzed the group of data which stratified by BCLC stage system to understand the significance of cortactin expression to the clinical stage. We simplified the BCLC stage into two stages: $0-B$ and C-D. Survival analysis stratified by simplified BCLC stage showed that in the stratum with BCLC stage 0-B, the median survival time was $63 \pm 5.93$ months in patients whose cortactin IHC score was $0-3$, which was much longer than those whose IHC score was $4-6$ ( $37 \pm 12.73$ months). The difference between the two IHC score levels was significant $(P=0.015)$ (Figure $11 C)$. In stratum with BCLC stage C-D, the significant difference was not found between cortactin IHC score level of $0-3$ and 4-6 $(P>0.05)$ (Figure 11D). These results suggest that, cortactin examination can get more accurate prediction in very early, early, and
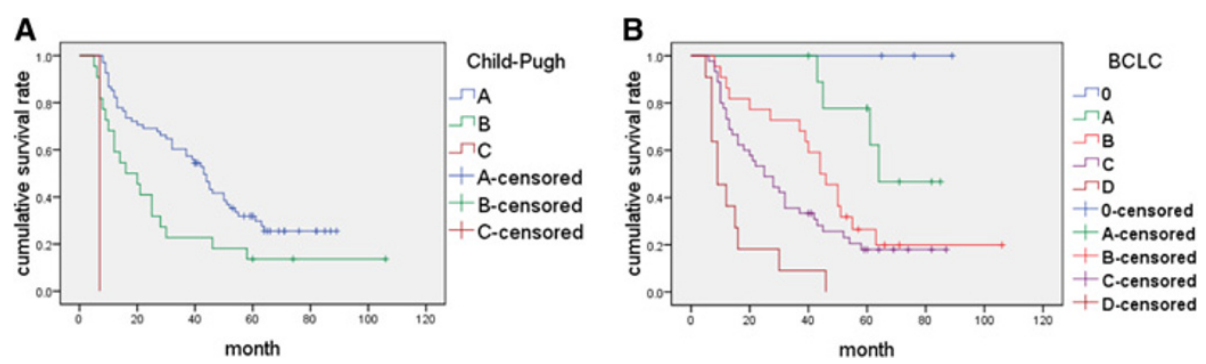

Figure 9 Survival analyses by Child-Pugh grade and BCLC stage. (A) Kaplan-Meier curves of 91 HCC patients grouped by Child-Pugh grades $A, B$, and $C(P<0.001)$; (B) Kaplan-Meier curves of 91 HCC patients grouped by BCLC stages $0, A, B, C$, and $D(P<0.001)$. 

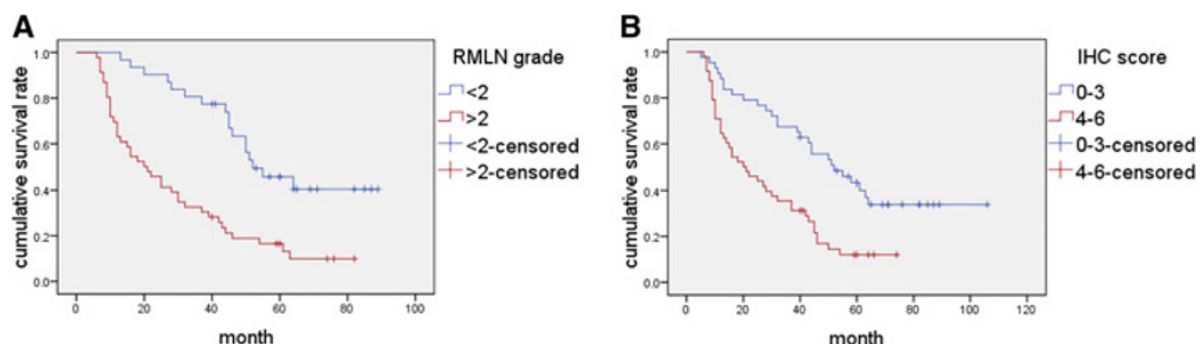

Figure 10 Survival analyses with two kinds of grouping method. (A) Kaplan-Meier curves of 77 HCC patients with CTTN RMLN grades of $<2$ and $>2(P<0.001)$; (B) Kaplan-Meier curves of 91 HCC patients with cortactin IHC score ranks of 0-3 and 4-6 $(P<0.001)$.

intermediate HCC. But it may do not apply to advanced and terminal HCC cases. The possible reason is that BCLC stage $C$ includes the cases that present vascular invasion or extrahepatic spread. This criterion consequentially weakens the power of cortactin forecasting role. Very interestingly, this weakening also demonstrates on the other hand that the high level of cortactin expression in HCC identifies a high capability of invasion and metastasis.

All the findings in our experiments support that cortactin and CTTN expression levels are correlated with the invasiveness and migration of $\mathrm{HCC}$ and give the evidence that overexpression of cortactin and CTTN mRNA contribute to HCC invasive and metastasis. Cortactin examination has more predictive power in patients with Child-Pugh grade A and BCLC stage 0-B. In addition to the satisfactorily predictive power to $\mathrm{HCC}$ prognosis, we also develop a valuable method that can precisely detect CTTN mRNA level with the advantage of sensitivity, specificity, and repeatability. This method can be used for other quantitative studies about CTTN expression. In conclusion, overexpression of cortactin is closely associated with poor prognosis in human HCC. Cortactin and CTTN should be used for differentiating varieties of survival for patients with $\mathrm{HCC}$.

\section{Conclusion}

Overexpression of cortactin is associated with high invasiveness of hepatoma carcinoma cells, which closely involved poor human HCCs prognosis that caused by cancer embolus and metastasis. Cortactin examination has more predictive power in patients with Child-Pugh grade A and BCLC stage $0-B$. As a sensitive biomarker, cortactin should be used for differentiating varieties of survival for patients after $\mathrm{HCC}$ resection.
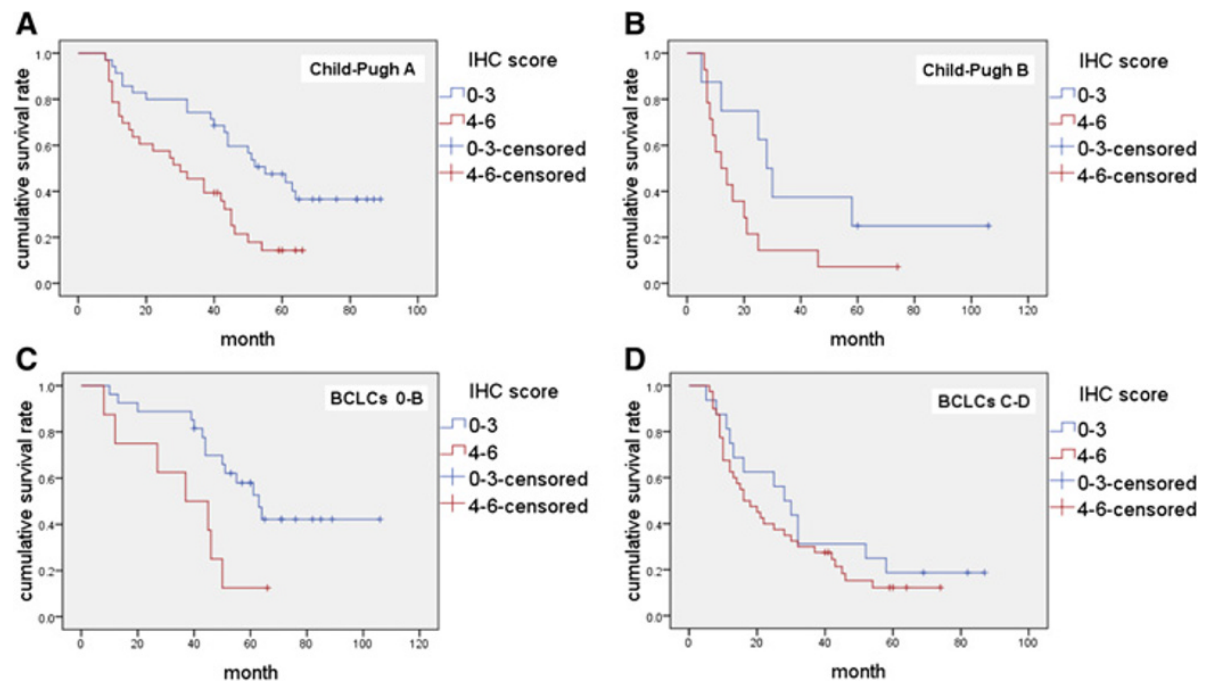

Figure 11 Survival analyses stratified by Child-Pugh grade and BCLC stage. (A) Kaplan-Meier curves of 68 HCC patients (stratum Child-Pugh A) with cortactin $\mathrm{IHC}$ score ranks of 0-3 and 4-6 ( $P<0.01)$; (B) Kaplan-Meier curves of 22 HCC patients (stratum Child-Pugh B) with cortactin IHC score ranks of 0-3 and 4-6 ( $P=0.071)$; (C) Kaplan-Meier curves of 35 HCC patients (stratum BCLC 0-B) with cortactin IHC score ranks of 0-3 and 4-6 ( $P=0.015)$; (D) Kaplan-Meier curves of 56 HCC patients (stratum BCLC C-D) with cortactin IHC score ranks of 0-3 and 4-6 $(P>0.05)$. 


\section{Abbreviations}

AFP: a-fetoprotein; Ct: Cycle values; DMEM: Dulbecco minimum essential medium; ECM: Extracellular matrix; FBS: Fetal bovine serum; GAPDH: Glyceraldehyde phosphate dehydrogenase; HCC: Hepatocellular carcinoma; IHC: Immunohistochemistry; N-WASP: Neural Wiskott-Aldrich syndrome protein; RMLN: Natural logarithm of relative magnitude; RT-PCR: Reverse transcription-polymerase chain reaction.

\section{Competing interests}

The authors declare that they have no competing interests.

\section{Authors' contributions}

ZG was the main initiator of this work, plus wrote and edited the English; HZM carried out the cell biological experiments; KYL prepared the liver tissue samples; ZG and WDQ performed the molecular biological experiments and analysis. LY and RL completed the pathological diagnosis and classification; ZG and HZM performed clinical and empirical data recoding and analysis; $\mathrm{ZHY}$ took all responsibility and was the corresponding author. The authors take full responsibility for the scope, direction, and content of the manuscript and have approved the submitted manuscript.

\section{Acknowledgements}

This study was supported by a grant from Chinese PLA Air Force General Hospital. The authors would like to thank Professor Xu Jin-bo, at Beijing Institute of Transfusion Medicine, for his assistance in providing open laboratory for the study.

\section{Sources of support}

Scientific Research Grants of Chinese PLA Air Force General Hospital.

\section{Author details}

${ }^{1}$ Department of Hepatobiliary Surgery, Chinese PLA Air Force General Hospital, No.30 Fucheng Road, Haidian District, Beijing 100142, China. ${ }^{2}$ Chinese PLA General Hospital \& PLA Medical School, Beijing, China. ${ }^{3}$ The Post-Graduate Institute of An Hui Medical University, Beijing, China. ${ }^{4}$ Beijing Institute of Transfusion Medicine, Beijing, China. ${ }^{5}$ Department of Pathology, Chinese PLA Air Force General Hospital, Beijing, China.

Received: 17 December 2012 Accepted: 10 March 2013

Published: 21 March 2013

\section{References}

1. Jemal A, Bray F, Center MM, Ferlay J, Ward E, Forman D: Global cancer statistics. CA Cancer J Clin 2011, 61:69-90.

2. Chen JG, Zhang SW, Chen WQ: Analysis of liver cancer mortality in the national retrospective sampling survey of death causes in China, 2004-2005. Zhonghua Yu Fang Yi Xue Za Zhi 2010, 44:383-389.

3. Qin $L X$, Tang $Z Y$ : The prognostic molecular markers in hepatocellular carcinoma. World J Gastroenterol 2002, 8:385-392.

4. Nagao T, Inoue S, Yoshimi F, Sodeyama M, Omori Y, Mizuta T, Kawano N, Morioka Y: Postoperative recurrence of hepatocellular carcinoma. Ann Surg 1990, 211:28-33.

5. Yamaguchi $\mathrm{H}$, Condeelis J: Regulation of the actin cytoskeleton in cancer cell migration and invasion. Biochim Biophys Acta 2007, 1773:642-652.

6. Chuma M, Sakamoto M, Yasuda J, Fujii G, Nakanishi K, Tsuchiya A, Ohta T, Asaka M, Hirohashi S: Overexpression of cortactin is involved in motility and metastasis of hepatocellular carcinoma. J Hepatol 2004, 41:629-636.

7. Rodrigo JP, Garcia LA, Ramos S, Lazo PS, Suarez C: EMS1 gene amplification correlates with poor prognosis in squamous cell carcinomas of the head and neck. Clin Cancer Res 2000, 6:3177-3182.

8. Hui R, Ball JR, Macmillan RD, Kenny FS, Prall OW, Campbell DH, Cornish AL, McClelland RA, Daly RJ, Forbes JF, Blamey RW, Musgrove EA, Robertson JF, Nicholson RI, Sutherland RL: EMS1 gene expression in primary breast cancer: relationship to cyclin D1 and oestrogen receptor expression and patient survival. Oncogene 1998, 17:1053-1059.

9. Patel AS, Schechter GL, Wasilenko WJ, Somers KD: Overexpression of EMS1/cortactin in NIH3T3 fibroblasts causes increased cell motility and invasion in vitro. Oncogene 1998, 16:3227-3232.

10. Artym W, Zhang Y, Seillier-Moiseiwitsch F, Yamada KM, Mueller SC: Dynamic interactions of cortactin and membrane type 1 matrix metalloproteinase at invadopodia: defining the stages of invadopodia formation and function. Cancer Res 2006, 66:3034-3043.

11. Hofman P, Butori C, Havet K, Hofman V, Selva E, Guevara N, Santini J, Van Obberghen-Schilling E: Prognostic significance of cortactin levels in head and neck squamous cell carcinoma: comparison with epidermal growth factor receptor status. Br J Cancer 2008, 98:956-964.

12. Forner A, Llovet JM, Bruix J: Hepatocellular carcinoma. Lancet 2012, 379:1245-1255.

13. Kai M, Irie M, Okutsu T, Inoue K, Ogonuki N, Miki H, Yokoyama M, Migishima R, Muguruma K, Fujimura H, Kohda T, Ogura A, Kaneko-Ishino T, Ishino F: The novel dominant mutation Dspd leads to a severe spermiogenesis defect in mice. Biol Reprod 2004, 70:1213-1221.

14. Wolff AC, Hammond ME, Schwartz JN, Hagerty KL, Allred DC, Cote RJ, Dowsett M, Fitzgibbons PL, Hanna WM, Langer A, McShane LM, Paik S, Pegram MD, Perez EA, Press MF, Rhodes A, Sturgeon C, Taube SE, Tubbs R, Vance GH, van de Vijver M, Wheeler TM, Hayes DF: American Society of Clinical Oncology/College of American Pathologists guideline recommendations for human epidermal growth factor receptor 2 testing in breast cancer. J Clin Oncol 2007, 25:118-145.

15. Birner $P$, Oberhuber $G$, Stani J, Reithofer $C$, Samonigg $H$, Hausmaninger $H$, Kubista E, Kwasny W, Kandioler-Eckersberger D, Gnant M, Jakesz R: Evaluation of the United States Food and Drug Administration-approved scoring and test system of HER-2 protein expression in breast cancer. Clin Cancer Res 2001, 7:1669-1675.

16. Paradis V, Bieche I, Dargere D, Laurendeau I, Laurent C, Bioulac Sage P, Degott C, Belghiti J, Vidaud M, Bedossa P: Molecular profiling of hepatocellular carcinomas (HCC) using a large-scale real-time RT-PCR approach: determination of a molecular diagnostic index. Am J Pathol 2003, 163:733-741

17. Bertino G, Ardiri A, Malaguarnera M, Malaguarnera G, Bertino N, Calvagno GS: Hepatocellualar carcinoma serum markers. Semin Oncol 2012, 39:410-433.

18. Bertino G, Ardiri AM, Calvagno GS, Bertino N, Boemi PM: Prognostic and diagnostic value of des-gamma-carboxy prothrombin in liver cancer. Drug News Perspect 2010, 23:498-508.

19. Llovet JM, Chen Y, Wurmbach E, Roayaie S, Fiel MI, Schwartz M, Thung SN, Khitrov G, Zhang W, Villanueva A, Battiston C, Mazzaferro V, Bruix J, Waxman S, Friedman SL: A molecular signature to discriminate dysplastic nodules from early hepatocellular carcinoma in HCV cirrhosis. Gastroenterology 2006, 131:1758-1767.

20. Wu H, Reynolds AB, Kanner SB, Vines RR, Parsons JT: Identification and characterization of a novel cytoskeleton-associated pp60src substrate. Mol Cell Biol 1991, 11:5113-5124.

21. Schuuring E, Verhoeven E, Litvinov S, Michalides RJ: The product of the EMS1 gene, amplified and overexpressed in human carcinomas, is homologous to a v-src substrate and is located in cell-substratum contact sites. Mol Cell Biol 1993, 13:2891-2898.

22. Schuuring E, Verhoeven E, Mooi WJ, Michalides RJ: Identification and cloning of two overexpressed genes, U21B31/PRAD1 and EMS1, within the amplified chromosome $11 \mathrm{q} 13$ region in human carcinomas. Oncogene 1992, 7:355-361.

23. Ormandy CJ, Musgrove EA, Hui R, Daly RJ, Sutherland RL: Cyclin D1, EMS1 and 11 q13 amplification in breast cancer. Breast Cancer Res Treat 2003 78:323-335.

24. Takes RP, de Jong RJB, Schuuring E, Hermans J, Vis AA, Litvinov SV, van Krieken $\mathrm{JH}$ : Markers for assessment of nodal metastasis in laryngeal carcinoma. Arch Otolaryngol Head Neck Surg 1997, 123:412-419.

25. Williams ME, Gaffey MJ, Weiss LM, Wilczynski SP, Schuuring E, Levine PA Chromosome 11Q13 amplification in head and neck squamous cell carcinoma. Arch Otolaryngol Head Neck Surg 1993, 119:1238-1243.

26. Wu H, Parsons JT: Cortactin, an 80/85-kilodalton pp60src substrate, is a filamentous actin-binding protein enriched in the cell cortex. J Cell Biol 1993, 120:1417-1426.

27. Weed SA, Parsons JT: Cortactin: coupling membrane dynamics to cortical actin assembly. Oncogene 2001, 20:6418-6434.

28. Uruno T, Liu J, Zhang P, Fan Y, Egile C, Li R, Mueller SC, Zhan X: Activation of Arp2/3 complex-mediated actin polymerization by cortactin. Nat Cell Biol 2001, 3:259-266

29. Weaver AM, Karginov AV, Kinley AW, Weed SA, Li Y, Parsons JT, Cooper JA: Cortactin promotes and stabilizes Arp2/3-induced actin filament network formation. Curr Biol 2001, 11:370-374. 
30. Kowalski JR, Egile C, Gil S, Snapper SB, Li R, Thomas SM: Cortactin regulates cell migration through activation of N-WASP. J Cell Sci 2005, 118:79-87.

31. Weaver AM, Heuser JE, Karginov AV, Lee WL, Parsons JT, Cooper JA: Interaction of cortactin and N-WASp with Arp2/3 complex. Curr Biol 2002, 12:1270-1278.

32. Huang C, Liu J, Haudenschild CC, Zhan X: The role of tyrosine phosphorylation of cortactin in the locomotion of endothelial cells. J Biol Chem 1998, 273:25770-25776.

33. Hill A, McFarlane $S$, Mulligan $K$, Gillespie $H$, Draffin JE, Trimble A, Ouhtit A, Johnston PG, Harkin DP, McCormick D, Waugh DJ: Cortactin underpins CD44-promoted invasion and adhesion of breast cancer cells to bone marrow endothelial cells. Oncogene 2006, 25:6079-6091.

34. Bryce NS, Clark ES, Leysath JL, Currie JD, Webb DJ, Weaver AM: Cortactin promotes cell motility by enhancing lamellipodial persistence. Curr Biol 2005, 15:1276-1285

35. Timpson P, Lynch DK, Schramek D, Walker F, Daly RJ: Cortactin overexpression inhibits ligand-induced down-regulation of the epidermal growth factor receptor. Cancer Res 2005, 65:3273-3280.

36. Clark ES, Whigham AS, Yarbrough WG, Weaver AM: Cortactin is an essentia regulator of matrix metalloproteinase secretion and extracellular matrix degradation in invadopodia. Cancer Res 2007, 67:4227-4235.

37. Roayaie S, Blume IN, Thung SN, Guido M, Fiel MI, Hiotis S, Labow DM, Llovet $J M$, Schwartz ME: A system of classifying microvascular invasion to predict outcome after resection in patients with hepatocellular carcinoma. Gastroenterology 2009, 137:850-855.

38. Choi KK, Kim SH, Choi SB, Lim JH, Choi GH, Choi JS, Kim KS: Portal venous invasion: the single most independent risk factor for immediate postoperative recurrence of hepatocellular carcinoma. J Gastroenterol Hepatol 2011, 26:1646-1651.

39. El-Assal ON, Yamanoi A, Soda Y, Yamaguchi M, Yu L, Nagasue N: Proposal of invasiveness score to predict recurrence and survival after curative hepatic resection for hepatocellular carcinoma. Surgery 1997, 122:571-577.

40. Iguchi T, Aishima S, Taketomi A, Nishihara Y, Fujita N, Sanefuji K, Maehara Y, Tsuneyoshi M: Extracapsular penetration is a new prognostic factor in human hepatocellular carcinoma. Am J Surg Pathol 2008, 32:1675-1682.

41. Cabibbo G, Enea M, Attanasio M, Bruix J, Craxi A, Camma C: A metaanalysis of survival rates of untreated patients in randomized clinical trials of hepatocellular carcinoma. Hepatology 2010, 51:1274-1283,

doi:10.1186/1477-7819-11-74

Cite this article as: Zhao et al: Cortactin is a sensitive biomarker relative to the poor prognosis of human hepatocellular carcinoma. World Journal of Surgical Oncology 2013 11:74.

\section{Submit your next manuscript to BioMed Central and take full advantage of:}

- Convenient online submission

- Thorough peer review

- No space constraints or color figure charges

- Immediate publication on acceptance

- Inclusion in PubMed, CAS, Scopus and Google Scholar

- Research which is freely available for redistribution 